\title{
Descrição de uma forma autossômica dominante de síndrome de Kabuki por mutação no gene $M L L 2$
}

\author{
Description of an autosomal dominant form of Kabuki syndrome by mutation \\ in MLL2 gene
}

\author{
Maria Inês Santos ${ }^{1}$, Ana Beleza-Meireles ${ }^{2}$, Susana Loureiro³, Margarida Fonseca ${ }^{4}$, Cláudia F. Reis ${ }^{2}$, \\ Fidjy Rodrigues 5 , Fabiana $\operatorname{Ramos}^{6}$, Lina $\operatorname{Ramos}^{6}$, Elisa Cardoso \\ 1 Interna Complementar de Pediatria. Serviço de Pediatria, Hospital de São Teotónio - Centro Hospitalar Tondela-Viseu, Viseu, Portugal. \\ 2 Interna Complementar de Genética Médica. Serviço de Genética Médica, Hospital Pediátrico Carmona da Mota - Centro Hospitalar e \\ Universitário de Coimbra, Coimbra, Portugal. \\ 3 Especialista em Pediatria. Assistente Hospitalar, Serviço de Pediatria, Hospital de São Teotónio - Centro Hospitalar Tondela-Viseu, Viseu, Portugal. \\ ${ }^{4}$ Especialista em Pediatria. Assistente Hospitalar, Serviço de Pediatria, Maternidade Bissaya Barreto, Centro Hospitalar e \\ Universitário de Coimbra, Coimbra, Portugal. \\ ${ }_{5}^{5}$ Psicóloga. Mestre em Aconselhamento Genético. Serviço de Genética Médica, Hospital Pediátrico Carmona da Mota - Centro Hospitalar e \\ Universitário de Coimbra, Coimbra, Portugal. \\ ${ }^{6}$ Especialista em Pediatria e Genética Médica. Assistente Hospitalar, Serviço de Genética Médica, Hospital Pediátrico Carmona da Mota - Centro Hospitalar e \\ Universitário de Coimbra, Coimbra, Portugal. \\ 7 Especialista em Pediatria. Coordenadora da Unidade de Desenvolvimento, Serviço de Pediatria, Hospital de São Teotónio - Centro Hospitalar Tondela-Viseu, \\ Viseu, Portugal. \\ ${ }^{8}$ Especialista em Pediatria e Genética Médica. Diretor do Serviço de Genética Médica, Hospital Pediátrico Carmona da Mota - Centro Hospitalar e \\ Universitário de Coimbra. Professor da Faculdade de Medicina da Universidade de Coimbra, Coimbra, Portugal.
}

\begin{abstract}
RESUMO
Objetivos: Apesar de existirem mais de 400 casos de síndrome de Kabuki descritos na literatura, pensa-se que a síndrome seja subdiagnosticada. A maioria dos casos ocorre de forma esporádica, mas são descritos alguns casos de transmissão familiar autossômica dominante. Descrevem-se aqui três casos identificados na mesma família.

Descrição dos casos: Uma família (mãe e dois filhos) foi diagnosticada com síndrome de Kabuki. Os três pacientes apresentam as características típicas (aparência facial característica, anomalias musculoesqueléticas, déficit cognitivo, atraso de crescimento pós-natal e padrão dermatoglífico peculiar) associadas a outras anomalias descritas na síndrome (cardiopatia congênita e suscetibilidade aumentada para infecções). O estudo genético revelou a mutação nonsense c.14710 C > T (p.Arg4904X) no gene MLL2 nos três membros da família.

Conclusões: Com a descrição de mais um caso familiar de síndrome de Kabuki, os autores pretendem ilustrar a hereditariedade autossômica dominante com expressividade variável presente nesta situação e alertar para a necessidade de uma rigorosa avaliação clínica e molecular dos familiares do afetado, permitindo um aconselhamento genético adequado.
\end{abstract}

\section{DESCRITORES: SÍNDROME DE KABUKI; MUTAÇÃO; TESTES GENÉTICOS}

\begin{abstract}
Aims: Although there are more than 400 cases of Kabuki syndrome described in the literature, it is believed that this syndrome is under-diagnosed. Most cases occur sporadically, despite cases with autosomal dominant familial transmission being described. Here we describe three cases identified in the same family.

Cases description: A family (mother and two children) was diagnosed with Kabuki syndrome. The three patients show the typical characteristics (facial appearance, musculoskeletal abnormalities, cognitive impairment, growth retardation and peculiar dermatoglyphic pattern) associated with other anomalies described in the syndrome (congenital heart disease and increased susceptibility to infections). Genetic studies revealed a nonsense mutation c.14710 C $>$ T (p.Arg4904X) in the MLL2 gene in the three members of the family.

Conclusions: With the description of another case of familial Kabuki syndrome, the authors wish to illustrate the autosomal dominant inheritance with variable expressivity, which are present in this situation, and to alert to the need for a rigorous clinical and molecular evaluation of the affected patient's relatives, allowing appropriate genetic counseling.
\end{abstract}

KEY WORDS: KABUKI SYNDROME; MUTATION; GENETIC TESTING 


\section{INTRODUÇÃO}

A síndrome de Kabuki (SK) foi inicialmente descrita em 1981 por Kuroki et al. ${ }^{1}$ e Niikawa et al. ${ }^{2}$ em publicações simultâneas e independentes. Kabuki make-up syndrome foi a nomenclatura inicialmente proposta por Niikawa et al. ${ }^{2}$ devido às semelhanças faciais entre indivíduos com essa síndrome e a elaborada maquilagem dos atores do teatro de Kabuki, como fendas palpebrais longas, ectrópio do terço externo da pálpebra inferior, sobrancelhas arqueadas com rarefacção pilosa do seu terço externo, pestanas longas e curvas, ponte nasal larga e ponta do nariz larga e deprimida. ${ }^{1-6}$

A SK inclui cinco características fundamentais, constituindo a Pêntade de Niikawa: dismorfismos faciais, anomalias musculoesqueléticas, déficit cognitivo, atraso de crescimento pós-natal e padrão dermatoglífico peculiar. ${ }^{3-5,7}$ Outros achados incluem cardiopatias congênitas, anomalias genitourinárias, fenda lábio-alvéolo-palatina, anomalias gastrointestinais, oculares e dentárias, suscetibilidade aumentada para infecções e doenças autoimunes, convulsões, problemas endócrinos e surdez. ${ }^{8}$

Existem mais de 400 casos de SK publicados na literatura, sendo que a prevalência descrita varia entre 1:86.000 e 1:32.000 nascimentos, ${ }^{6}$ provavelmente subestimada. ${ }^{3,5,6}$ Existem casos descritos em ambos os sexos e em todas as raças. ${ }^{6}$ É habitualmente esporádica, apesar de estarem descritos 17 casos com transmissão familiar autossômica dominante. . $^{3,5,6,9}$ Após dados iniciais controversos que associavam a síndrome a rearranjos cromossômicos, ${ }^{10}$ a identificação da mutação no gene $M L L 2$ permitiu a descoberta da causa da SK em 56 a 76\% dos indivíduos afetados. ${ }^{6,8,10}$ Mais recentemente, um grupo de pesquisa belga descobriu o envolvimento do gene KDM6A num pequeno grupo sem mutação no $M L L 2 .{ }^{11}$ Esse gene regula a atividade genética de $M L L 2$ nos processos de controle epigenéticos e pode ser resposável por casos de SK mesmo na ausência de mutações no MLL2. ${ }^{11}$

No presente artigo, descrevemos uma família (mãe e dois filhos) na qual foi feito o diagnóstico clínico de SK, posteriormente confirmado através de estudo genético. A responsável legal pelas crianças e a mãe das crianças, após terem sido devidamente informadas, assinaram um termo de consentimento autorizando a publicação dos relatos e das fotografias dos pacientes em revista científica. Foram observados todos os preceitos éticos contidos na Resolução 196 do Conselho Nacional da Saúde do Brasil, que estabelece as diretrizes e normas regulamentadoras de pesquisas envolvendo seres humanos.

\section{RELATO DOS CASOS}

\section{Caso 1}

Um menino, atualmente com 10 anos de idade, foi fruto de uma primeira gravidez vigiada e sem intercorrências de pais jovens e não consanguíneos. A mãe tinha um déficit cognitivo moderado, sem diagnóstico etiológico. O parto foi eutócico, com 39 semanas de gestação, com parâmetros somatométricos normais (peso e comprimento entre os percentis $10 \mathrm{e}$ 25 e perímetro cefálico no percentil 50).

No período neonatal apresentou sopro cardíaco, sendo diagnosticada uma comunicação interventricular sub-aórtica. Por apresentar má progressão ponderal, foi submetido a correção cirúrgica da cardiopatia aos dois meses de idade. Manteve, porém, má evolução pondoestatural acrescida de microcefalia (peso, estatura e perímetro cefálico eram inferiores ao percentil 5 para idade e sexo), além de atraso do neurodesenvolvimento, hipotonia e hiperlaxidão ligamentar. Há referência a dificuldades alimentares desde os três meses de vida. $\mathrm{O}$ seu perfil de desenvolvimento, avaliado pela Escala de Desenvolvimento Mental de Ruth Griffiths, aos 8 anos e 11 meses, revelou um Quociente de Desenvolvimento Global de 66 com déficit em todas as áreas mas mais evidentes nas escalas linguagem (Quociente de Desenvolvimento 59) e raciocínio prático (Quociente de Desenvolvimento 63).

Durante os primeiros dois anos de vida teve infecções respiratórias e gastrointestinais de repetição, que mantém apesar de menos frequentemente, tendo sido excluída imunodeficiência. Ao longo desse período foi realizada uma avaliação complementar extensa, incluindo estudos de imagem, metabólicos e genéticos, que foi inconclusiva. Com o crescimento foram-se tornando evidentes alguns dismorfismos característicos (Figura 1): fronte proeminente, fendas palpebrais longas com ectrópio do terço externo da pálpebra inferior, sobrancelhas arqueadas com rarefação pilosa do terço externo, pestanas longas e curvas, ponte e ponta do nariz largas, filtro e columela curtos, lábios finos com eversão do lábio inferior, baixa implantação do cabelo, pavilhões auriculares grandes, proeminentes e com implantação baixa, braquidactilia com hipoplasia das unhas, padrão dermatoglífico fetal e camptodactilia dos segundos dedos dos pés. Frente a esses achados clínicos, foi feito o diagnóstico clínico de SK na avaliação em Clínica de Genética aos dois anos de idade. 


\section{Caso 2}

Irmã do menino descrito como caso 1 , três anos mais moça, filha dos mesmos pais, foi fruto de uma gravidez vigiada e sem intercorrências, com parto distócico auxiliado por vácuo-extrator. Nasceu com parâmetros somatométricos normais (peso e perímetro cefálico no percentil 25 e comprimento no percentil 50). Luxação congênita de quadril bilateral, detectada no período neonatal. Apresentou má evolução pondoestatural desde os primeiros meses de vida, microcefalia, atraso do desenvolvimento neuromotor, astigmatismo e infecções de repetição (diarreias infecciosas, uma pneumonia complicada com derrame pleural e uma pielonefrite aguda). Por volta dos 18 meses verificou-se recuperação ponderal, encontrando-se actualmente no percentil 50 para sexo e idade. No entanto, manteve sempre baixa estatura e microcefalia (ambos os parâmetro abaixo do percentil 5). O Quociente de Desenvolvimento Global foi de 78 avaliado pela Escala de Desenvolvimento Mental de Ruth Griffiths, aos 5 anos e 8 meses, sendo a realização a sua área mais fraca (Quociente de Desenvolvimento 74), seguida da motora, linguagem e coordenação olho-mão (Quociente de Desenvolvimento 76).

Apresenta dismorfismos semelhantes aos do irmão, associando-se retrognatismo e escleras azuladas (Figura 2). Não foram detectadas anomalias cardíacas ou renais. Aos quatro anos de idade foi referenciada à Clínica de Genética, tendo sido feito o mesmo diagnóstico do irmão.

\section{Caso 3}

Mãe das duas crianças, residia numa instituição de apoio a doentes com déficit cognitivo moderado a grave. Habitualmente não acompanhava as crianças às consultas hospitalares, papel que era desempenhado pela avó paterna, tutora legal.

Após o diagnóstico dos dois filhos, solicitou-se a avaliação da mãe (Figura 3). Apresentava, além de déficit intelectual, luxação recorrente das rótulas, baixa estatura e dismorfismos faciais típicos, mas menos exuberantes que os das crianças, pelo que se fez o diagnóstico clínico de SK. Não foram encontradas outras anomalias concomitantes além das manifestações descritas.

Em 2011 foi realizado o estudo do gene MLL2 que revelou a mutação nonsense c.14710 C $>\mathrm{T}$ (p.Arg4904X), confirmando o diagnóstico nos três membros da família.

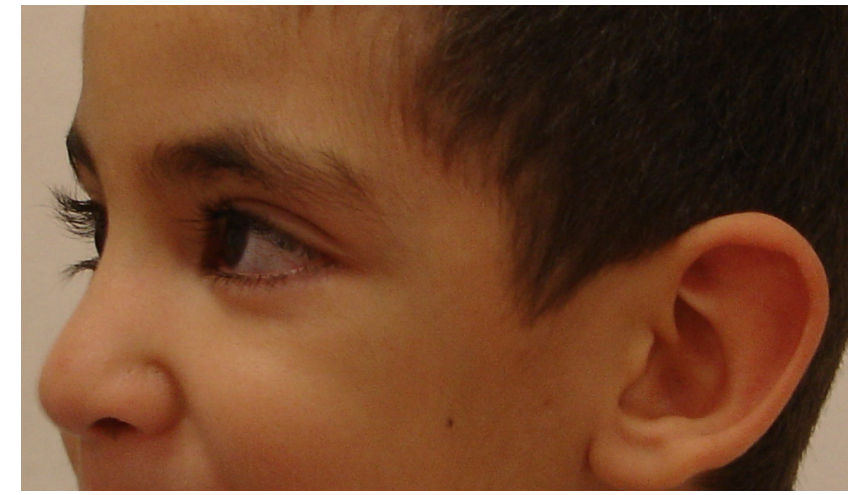

Figura 1. Caso 1 - Dismorfismos faciais típicos de síndrome de Kabuki em menino de 10 anos de idade. Fronte proeminente, baixa implantação do cabelo, fendas palpebrais longas com ectrópio do terço externo da pálpebra inferior, sobrancelhas arqueadas com rarefação pilosa do terço externo, pestanas longas e curvas, pavilhões auriculares grandes e proeminentes, ponte e ponta do nariz largas, filtro e columela curtos.

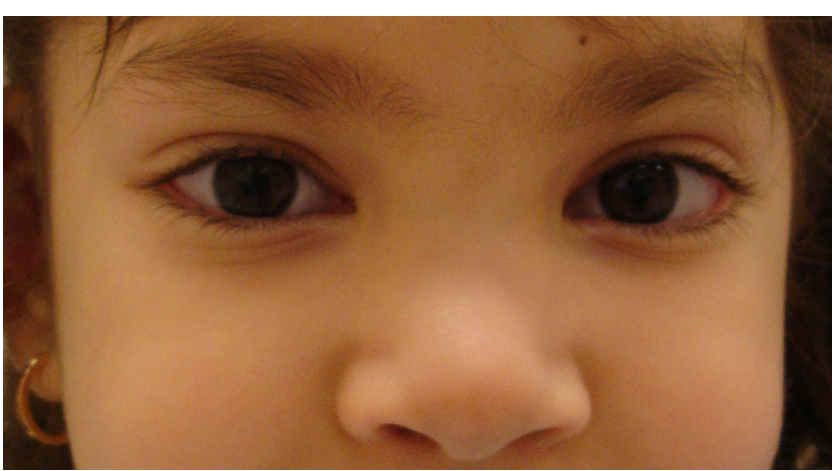

Figura 2. Caso 2 - Menina de 7 anos de idade, irmã do menino do caso 1. Dismorfismos semelhantes aos do irmão, associando-se escleras azuladas. Além dos dismofirmos faciais visíveis nas fotos, essas crianças apresentavam outras anomalias características da síndrome de Kabuki, incluindo retrognatismo, lábios finos com eversão do lábio inferior, anomalias musculoesqueléticas, déficit cognitivo, atraso de crescimento pós-natal, padrão dermatoglífico peculiar, susceptibilidade aumentada para infecções e outras malformações congênitas.

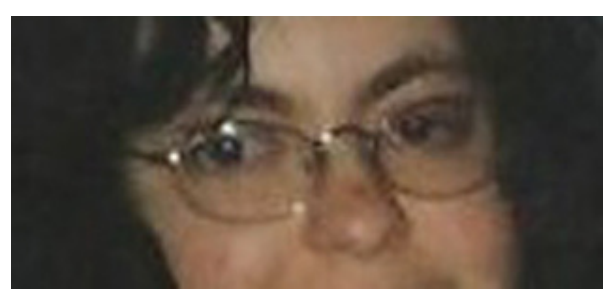

Figura 3. Caso 3 - Mãe das crianças dos casos 1 e 2 . Teve o diagnóstico da síndrome de Kabuki confirmado após a identificação da síndrome em seus filhos. Dismorfismos faciais típicos, mas menos exuberantes que os das crianças. Apresentava também déficit intelectual, luxação recorrente das rótulas e baixa estatura. $\mathrm{O}$ estudo genético mostrou mutação c.14710 C>T (p.Arg4904X) do gene MLL2 nos três membros da família. 


\section{DISCUSSÃO}

Apesar da maioria dos casos conhecidos de SK serem esporádicos, ${ }^{4}$ os casos presentes caracterizam a ocorrência familiar da síndrome. Nesta família, uma mãe com déficit intelectual e um pai saudável tiveram dois filhos afetados, o que suporta a transmissão autossômica dominante já descrita. ${ }^{3,7,8}$

A principal característica dos indivíduos com SKé a presença dos dismorfismos faciais característicos, ${ }^{3,6}$ tal como observado nos três casos descritos neste artigo. Apesar de a identificação do gene $M L L 2$ em doentes com SK ser recente, alguns estudos sugerem que mutações nesse gene associam-se mais frequentemente a características faciais clássicas da síndrome, ${ }^{8,12}$ bem como a uma maior incidência de baixa estatura, ${ }^{13} \mathrm{de}$ dificuldades alimentares e de luxações articulares, ${ }^{14}$ achados também presentes nos casos descritos. Perante essa mutação, estão também descritas frequências significativamente superiores de anomalias renais, ${ }^{12}$ fendas labio-alvéolo-palatinas e telarca precoce. ${ }^{14}$

Além destes achados, as crianças com SK podem apresentar má evolução pondoestatural pós-natal (35$81 \%$ ) com ou sem microcefalia, ${ }^{8}$ infecções recorrentes ${ }^{4}$ cardiopatia congênita $(40-50 \%),{ }^{8,15}$ hipotonia neonatal (25-89\%) e anomalias oculares, ${ }^{8}$ que ocorreram nos casos aqui apresentados. Alguns autores sugerem que a presença de atraso do neurodesenvolvimento não é obrigatória para o diagnóstico. ${ }^{6}$ Não está descrito um perfil cognitivo típico, no entanto existe alguma evidência de que algumas áreas, como a linguagem expressiva, a construção gramatical e a percepção visuo-espacial, sejam particularmente afetadas nesses doentes. ${ }^{8}$ Ambos os irmãos apresentavam maiores dificuldades na área da linguagem.

No sistema musculoesquelético, além das luxações articulares, estão descritas várias outras anomalias, como escoliose, malformações da coluna vertebral e costelas, atraso da maturação óssea, hipoplasia da segunda falange do quinto dedo, encurtamento dos metacarpos, braquidactilia, clinodactilia e hiperlaxidão ligamentar., ${ }^{4,5}$ Estão ainda descritas malformações genitourinárias $(25 \%)$, anomalias dentárias, refluxo gastroesofágico, convulsões, hipoacúsia $(40 \%)$ e doenças autoimunes. ${ }^{8}$ Essas características não foram encontradas nesta família.

Encontra-se publicada uma norma de orientação clínica para o acompanhamento de doentes com SK, ${ }^{16}$ baseada nas possíveis complicações que são previsíveis nas diferentes idades. Na infância precoce é importante realizar avaliações para pesquisar a presença de malformações associadas. Deve ainda proceder-se à avaliação regular da evolução pondoestatural, do neurodesenvolvimento, da visão e audição e de eventuais problemas endocrinológicos, pelo que é essencial uma abordagem multidisciplinar.

Apesar do diagnóstico ser primariamente baseado em achados clínicos, atualmente é possível a confirmação através do estudo do gene $M L L 2$ (sequenciação) em cerca de $75 \%$ dos doentes, ${ }^{8,15}$ sendo previsível uma grande heterogeneidade alélica. A maioria das mutações são nonsense e frameshift. ${ }^{8} \mathrm{De}$ acordo com o conhecimento atual, a penetrância parece ser completa. ${ }^{8}$ A proteína MLL2 é um membro da Mixed Lineage Leukemia (MLL) envolvida na embriogênese e desenvolvimento, por exemplo, através da regulação da expressão dos genes $H O X$ e da sua interação com receptores nucleares. ${ }^{15} \mathrm{O}$ estudo molecular e a identificação de uma mutação patogênica permite não só a confirmação do diagnóstico, mas também o diagnóstico pré-natal e mesmo pré-implantação. Também têm sido descritas mutações no gene KDM6A (300128) no cromossoma Xp11.3 em alguns casos. ${ }^{11}$

O diagnóstico precoce da SK é essencial, já que permite não só o aconselhamento genético específico à família, mas também uma abordagem multidisciplinar e eficaz na detecção e orientação dos problemas encontrados, conduzindo a uma melhoria no prognóstico e na qualidade de vida. Apesar do crescente conhecimento de casos com mutações no gene MLL2, estudos de casos familiares poderão complementar o estudo da expressividade fenotípica da síndrome em indivíduos com a mesma mutação. Com a descrição destes casos familiares, que ilustram a hereditariedade autossômica dominante com expressividade variável desta síndrome, pretendemos alertar os profissionais de saúde infantil para a necessidade de uma rigorosa avaliação clínica e molecular (nos casos com mutação identificada) dos familiares do indivíduo afetado, no sentido de identificar casos familiares, permitindo um aconselhamento genético adequado e o oferecimento de diagnóstico molecular pré-natal e pré-implantação.

\section{AGRADECIMENTOS}

Os autores agradecem à Dra. Gabriela Laranjo, à Dra. Catarina Resende e ao Dr. Pedro Fernandes pela contribuição na avaliação clínica e acompanhamento das crianças.

\section{REFERÊNCIAS}

1. Kuroki Y, Suzuki Y, Chyo H, et al. A new malformation syndrome of long palpebral fissures, large ears, depressed nasal tip, and skeletal anomalies associated with postnatal dwarfism and mental retardation. J Pediatr 1981;99: 570-3. 
2. Niikawa N, Matsuura N, Fukushima Y, et al. Kabuki makeup syndrome: a syndrome of mental retardation, unusual facies, large and protruding ears, and postnatal growth deficiency. J Pediatr 1981;99:565-9.

3. Dupont J, Dias P, Medeira A, et al. Síndrome de Kabuki: caracterização de 16 doentes portugueses. Acta Pediatr Port 2010;41:86-91.

4. Hou JW. Variable expressivity in a family with Kabuki make-up (Niikawa-Kuroki) syndrome. Chang Gung Med J. 2004;27:307-11.

5. Gabrieli APT, Rovaris FV, Bisol LE, et al. Síndrome da maquiagem de kabuki. Acta Ortop Bras. 2002;10:57-61.

6. Suarez Guerrero JL, Ordónez Suarez AA, Contreras García GA. Síndrome de Kabuki. An Pediatr (Barc) 2012;77:51-6.

7. Van Bever Y, van den Ende JJ. Brief clinical report: the Kabuki make-up syndrome in a Brazilian boy. Rev Bras Genét. 1992;15:973-7.

8. Adam MP, Hudgins L, Hannibal M. Kabuki Syndrome. 2011 Sep 1. In: Pagon RA, Bird TD, Dolan CR, et al., editors. GeneReviews $^{\text {TM }}$ [Internet]. Seattle (WA): University of Washington; 1993- [revised 2011 Set]. [capturado 2013 jan 24];[11 telas]. Disponível em: http://www.ncbi.nlm.nih.gov/ books/NBK62111

9. Kokitsu-Nakata NM, Petrin AL, Heard JP, et al. Analysis of MLL2 gene in the first Brazilian family with Kabuki syndrome. Am J Med Genet 2012;158:2003-8.
10. Micale L, Augello B, Fusco C, et al. Mutation spectrum of MLL2 in a cohort of kabuki syndrome patients. Orphanet J Rare Dis 2011;6:1-8.

11. Lederer D, Grisart B, Digilio M, et al. Deletion of KDM6A, a histone demethylase interacting with MLL2, in three patients with Kabuki syndrome. Am J Hum Genet 2012;90: 119-24.

12. Hannibal MC, Buckingham KJ, Ng SB et al. Spectrum of MLL2 (ALR) mutations in 110 cases of Kabuki syndrome. Am J Med Genet 2011;155A:1511-6.

13. Paulussen AD, Stegmann AP, Blok MJ et al. MLL2 mutation spectrum in 45 patients with Kabuki syndrome. Hum Mutat 2011;32:E2018-25.

14. Banka S, Veeramachaneni R, Reardon W et al. How genetically heterogeneous is Kabuki syndrome? MLL2 testing in 116 patients, review and analyses of mutation and phenotypic spectrum. Eur J Hum Genet. 2012;20: 381-8.

15. Ohdo S, Madokoro H, Sonoda T, et al. Kabuki make-up syndrome (Niikawa-Kuroki syndrome) associated with congenital heart disease. J Med Genet 1985;22:126-7.

16. Philip N, Devriendt K, Clayton-Smith J. Management of Kabuki Syndrome: a clinical guideline [Internet]. Version 1. [Manchester]: Dyscerne; c2010 [revisado 2011 Mar 8; capturado 2013 Jan 15]. Disponível em: http://www.dyscerne. org/dysc/digitalAssets/0/264_Kabuki_Guidelines.pdf 